\title{
Copper chloride dose-dependently alters spatial learning and memory, and glutamate levels, in the hippocampus of rats
}

\author{
GUISHAN ZHANG $^{1 *}$, QI LI $^{2 *}$, WENHUA GAO ${ }^{2}$, SHAOWEN LIU ${ }^{3}$, RENHUA WU $^{4}$, \\ ZHIWEI SHEN ${ }^{4}$, WENHUA LIU ${ }^{2}$ and YAOWEN CHEN ${ }^{1}$ \\ ${ }^{1}$ Key Laboratory of Digital Signal and Image Processing of Guangdong; \\ ${ }^{2}$ Science College of Shantou University, Shantou, Guangdong 515063; ${ }^{3}$ Mental Health Center, \\ Shantou University Medical College, Shantou, Guangdong 515065; ${ }^{4}$ Department of Medical Imaging, \\ The Second Affiliated Hospital, Shantou University Medical College, Shantou, Guangdong 515041, P.R. China
}

Received August 4, 2016; Accepted August 8, 2017

DOI: $10.3892 / \mathrm{mmr} .2017 .8278$

\begin{abstract}
Copper is a trace element which exerts an important role in neuronal functions. Excessive $\mathrm{Cu}$ exposure is associated with central nervous system dysfunction, including memory loss. The present study examined the effects of $\mathrm{CuCl}_{2}$ exposure on the spatial learning and memory of rats, and on metabolites in the hippocampus. A total of 60 male Sprague-Dawley rats (10 rats/group) were intraperitoneally injected with various doses $(0,0.5,1.0,2.0,4.0$ and $6.0 \mathrm{mg} / \mathrm{kg})$ of $\mathrm{CuCl}_{2}$ three times every other day for 6 days. Rats administered with $1.0 \mathrm{ml} / \mathrm{kg}$ sterile saline were used as controls. A total of 2 days subsequent to the final injection, the rats were subjected to the Morris water maze (MWM) test, followed by
\end{abstract}

Correspondence to: Professor Yaowen Chen, Key Laboratory of Digital Signal and Image Processing of Guangdong, 243 Daxue Road, Shantou, Guangdong 515063, P.R. China

E-mail: ywchen@stu.edu.cn

Professor Wenhua Liu, Science College of Shantou University, 243 Daxue Road, Shantou, Guangdong 515063, P.R. China

E-mail:whliu@stu.edu.cn

${ }^{*}$ Contributed equally

Abbreviations: CNS, central nervous system; GABA, $\gamma$-aminobutyric acid; Glu, glutamate; HPLC, high performance liquid chromatography; VOI, volume of interest; MWM, Morris water maze; TR, repetition time; TE, echo time; $\mathrm{Cr}$, creatine; Gln, glutamine; GPC, glycerophosphorylcholine; mI, myo-inositol; NAA, N-acetyl-L-aspartate; NAAG, N-acetylaspartylglutamate; PCh, phosphorylcholine; PCr, phosphocreatine; Tau, taurine; MRS, magnetic resonance spectroscopy; AD, Alzheimer's disease; ROS, reactive oxygen species; GluNR, N-methyl-D-aspartic acid glutamate receptor; S-D, Sprague-Dawley; Tau, taurine; SOD1, superoxide dismutase; MDA, malondialdehyde; AMPA, $\alpha$-amino-3-hydroxy-5-methyl-4-isoxazolepropionic acid

Key words: copper, magnetic resonance spectroscopy, brain metabolites, cognitive function, hippocampus proton magnetic resonance spectroscopy $\left({ }^{1} \mathrm{H}-\mathrm{MRS}\right)$. The rats were subsequently sacrificed, and their hippocampal tissues were processed for high performance liquid chromatography (HPLC). The MWM test demonstrated that the high-dose groups exhibited worse spatial learning and memory compared with the controls; however, the rats that received a relatively low dose $(2.0 \mathrm{mg} / \mathrm{kg})$ exhibited a decreased impairment. The ${ }^{1} \mathrm{H}-\mathrm{MRS}$ results revealed increased Glu, N-acetyl-L-aspartate (NAA)+N-acetylaspartylglutamate, phosphocreatine (PCr) and $\mathrm{Cr}+\mathrm{PCr}$ levels in the hippocampus of the $2.0 \mathrm{mg} / \mathrm{kg}$ group. HPLC analysis revealed increased $\gamma$-aminobutyric acid and glutamate (Glu) levels in the $2.0 \mathrm{mg} / \mathrm{kg}$ group, and decreased Glu levels in the $6.0 \mathrm{mg} / \mathrm{kg}$ group. The results of the present study demonstrated a beneficial effect of short-term exposure to a relatively low dose of $\mathrm{CuCl}_{2}$ on spatial learning and memory, and the association of this effect with increased NAA and Glu levels in the hippocampus.

\section{Introduction}

Copper is a trace element that is important for neuronal functions. Additionally, it is a cofactor of enzymes and proteins that are required for a number of physiological functions, including neural transmission, the scavenging of free radicals, the production of energy and the mobilization of iron $(1,2)$. As an important cofactor of metalloproteins, $\mathrm{Cu}$ ions act as an active or structural site. However, excessive exposure to $\mathrm{Cu}$ has been associated with central nervous system (CNS) dysfunction, including memory loss, multiple neuritis and neurasthenia syndrome $(3,4)$. Additionally, post-mortem studies have demonstrated that $\mathrm{Cu}$ levels are markedly elevated in the brains of patients with Alzheimer's disease (AD) (5). The neurotoxicity caused by excessive $\mathrm{Cu}$ is thought to be an important risk factor for cognitive impairment in the ageing population, particularly learning and memory impairment (6).

Numerous studies have associated chronic $\mathrm{Cu}$ intoxication with AD-like pathology (7). For example, treating primary hippocampal neurons (10-14 days in vitro) with $\mathrm{CuCl}_{2}$ (up to $10 \mu \mathrm{M}$ ) for $3 \mathrm{~h}$ was observed to significantly increase the amplitude, frequency and time constants of synaptic events (8). In addition, $\mathrm{Cu}$ has been demonstrated to be involved in the 
synthesis of phosphatidyl-L-serine and phosphatidyl inositide complexes through a process that required ATP-mediated regulation (9).

Mitochondria are an energy-producing organelle and are thus vital for cell survival. $\mathrm{Cu}$ is involved in a number of signalling cascades and has been hypothesised to serve important roles in neurodegenerative processes associated with respiratory chain dysfunction and the generation of reactive oxygen species (ROS). $\mathrm{Cu}$ is considered to be a co-factor for complex IV of the mitochondrial electron transport chain and for cytochrome c oxidase. Notably, $\mathrm{Cu}$ deficiency has been observed to impair brain development, as it impaired mitochondrial function and led to a disorder of brain energy metabolism (10). Conversely, previous studies have reported $\mathrm{Cu}$ concentrations as high as 200 or $400 \mu \mathrm{M}$ in neurodegenerative diseases $(11,12)$. As co-factors of certain enzymes, $\mathrm{Cu}$ ions are involved in the generation of ATP and the degradation of ROS in mitochondria.

$\gamma$-aminobutyric acid (GABA) is recognized as an important inhibitory neurotransmitter in the brain, while glutamate (Glu) functions as an excitatory neurotransmitter; in the brain, these transmitters serve a role in cognitive functions, including learning and memory. $\mathrm{Cu}$ has been observed to dampen $\mathrm{GABA}_{\mathrm{A}}$ and Glu receptor function (13-15). A previous study proposed a link between $\mathrm{Cu}$ and the activity of the N-methyl-D-aspartic acid subtype of Glu receptors (GluNRs), with a functional link between $\mathrm{Cu}$ homeostasis and GluNR activity (16). In the present study, neurometabolites in the hippocampus of rats acutely exposed to various doses of $\mathrm{CuCl}_{2}$ were measured via proton magnetic resonance spectroscopy ( $\left.{ }^{1} \mathrm{H}-\mathrm{MRS}\right)$ and high-performance liquid chromatography (HPLC), and the spatial learning and memory of the animals were evaluated. The spatial learning and memory of the rats were affected in a dose-dependent manner and the beneficial effect of a relatively low dose of $\mathrm{CuCl}_{2}$ was associated with a mild increase in Glu in the hippocampus of the rats.

\section{Materials and methods}

Animals and experimental design. A total of 60 male Sprague-Dawley (S-D) rats (age, 7 weeks; weight, 200 \pm 34 g) were used in the present study. The animals were purchased from the Experimental Animal Center of Shantou University Medical College (Shantou, China) and were group housed (7-8 rats/cage) under standard laboratory conditions $\left(22 \pm 1^{\circ} \mathrm{C}\right.$ temperature and $5 \pm 4 \%$ humidity) on a 12 -h light/dark cycle (7:00 a.m. on; 7:00 p.m. off). Standard rat diet and water were given ad libitum. Following 7 days of acclimatization, the rats were randomly and equally divided into six groups (10 rats/group). Various doses $(0,0.5,1.0,2.0,4.0$ and $6.0 \mathrm{mg} / \mathrm{kg}$ ) of $\mathrm{CuCl}_{2}$ (Yuanye Biotechnology, Co., Ltd., Shanghai, China) in sterilized saline were given to the rats by intraperitoneal injection three times every other day for a 6-day period. The injection volume was $1.0 \mathrm{ml} / \mathrm{kg}$. A total of 2 days subsequent to the last injection, all rats were subjected to the Morris water maze (MWM) test to evaluate hippocampus-dependent spatial learning and memory abilities. One training test was performed each day for 4 consecutive days, followed by one probe test on the 5th day. A total of $24 \mathrm{~h}$ subsequently, the rats were subjected to magnetic resonance imaging (MRI) and the ${ }^{1} \mathrm{H}-\mathrm{MRS}$ procedure. Subsequently, the rats were sacrificed and their brains were removed. The right hippocampus was dissected out on ice and stored at $-80^{\circ} \mathrm{C}$ for subsequent HPLC analysis. All animal procedures were performed in accordance with the guidelines set up by the Animal Care and Use Committee of Shantou University Medical College and were approved by the committee.

MWM test. The conventional MWM test was performed to evaluate the spatial learning and reference memory abilities of the rats (17). As previously described, the rats were placed in a circular white tank with a diameter of $120 \mathrm{~cm}$ and a depth of $50 \mathrm{~cm}$. The tank was filled with opacified water $\left(25 \pm 1^{\circ} \mathrm{C}\right)$ to a height of $38 \mathrm{~cm}$ and was surrounded by dark geometric cues affixed to white curtains $(18,19)$. The tank was divided into four imaginary quadrants (quadrants I, II, III and IV), and an escape platform was positioned $2 \mathrm{~cm}$ under the horizontal plane in the middle of quadrant II. The MWM test consisted of two phases: The place navigation test and the spatial probe test.

All rats were habituated to the maze 1 day prior to training. During the place navigation training session, each rat was placed into the tank at a randomly selected position and allowed to explore the pool using a systematic or random search strategy. The behaviour of the rats in the water maze was videotaped using a video camera suspended above the maze that interfaced with a computer-based video tracking system. One navigation test was completed each day for 4 consecutive days, followed by one spatial probe test on the 5th day.

The platform was submerged during the training. During the place navigation trial, the rats were placed in the water and were allowed to search for the submerged platform for $60 \mathrm{sec}$. If the rat failed to find the platform, the operator moved it to the platform, where it remained for $20 \mathrm{sec}$. The escape latency was measured as described previously (18).

On the first day following 4 days of training sessions, a probe trial was completed. The platform was removed, and the rat was placed into the water in the quadrant opposite the target quadrant (quadrant II) and allowed to swim for $120 \mathrm{sec}$. Rats that failed to locate the platform within $120 \mathrm{sec}$ were manually guided to the platform and kept there for $20 \mathrm{sec}$. As the rats swam around the pool, various parameters, including the number of platform crossings, the time required to reach the platform, the ratio of distance travelled in the target quadrant, the percentage time spent in the target platform quadrant, the total distance and the average travel speed were recorded using the DigBehav-Morris Water Maze Video Analysis System (Jiliang Software Technology Co., Ltd., Shanghai, China). When all tasks had been completed, the rats were dried and placed back into the housing facility once their body temperature had returned to a normal level $\left(36-37^{\circ} \mathrm{C}\right)$.

MRI/MRS acquisition. The in vivo MRI/MRS experiments were performed using a horizontal bore (bore size, $160 \mathrm{~mm}$ ) Agilent 7.0 Tesla animal MRI scanner (Agilent Technologies, Inc., Santa Clara, CA, USA), equipped with a $20-\mathrm{mm}$ standard one-channel ${ }^{1} \mathrm{H}$ volume coil for radio frequency transmission and reception. The rats were initially anaesthetised with $5 \%$ isoflurane (Abbott Pharmaceutical Co., Ltd., Lake Bluff, IL, USA) in oxygen and continuously anaesthetised with the $1-2 \%$ isoflurane 
(for maintenance), which was delivered through a nasal mask for spontaneous respiration. Following anaesthetisation, each rat was placed in a prone position in the centre region of the horizontal bore with its head fixed on a palate holder equipped with an adjustable nose cone for MRI/MRS acquisition. Body temperature was recorded through the respiration system and was maintained at $36-37^{\circ} \mathrm{C}$ using a plastic membrane.

In order to ensure high image quality, the target must be placed in the centre of the magnet. In order to achieve correct positioning, images of the head in three planes were acquired with a gradient echo sequence. Subsequently, T2-weighted images in coronal, sagittal and axial positions were obtained using a fast spin echo multi-slice pulse sequence with the following parameters: Field of view $=23 \times 19 \mathrm{~mm}^{2}$; matrix size $=256 \times 256$; repetition time $(\mathrm{TR})=2,000 \mathrm{msec}$; effec tive echo time $(\mathrm{TE})=31.58 \mathrm{msec}$; slice thickness $=2 \mathrm{~mm}$; slice gap $=0.5 \mathrm{~mm}$; and acquisition time $=4 \mathrm{~min} 20 \mathrm{sec}$. The high-resolution T2-weighted images were used to position the ${ }^{1} \mathrm{H}-\mathrm{MRS}$ voxels in the hippocampus.

Following morphological imaging, the volume of interest (VOI) was located by referring to a digital rat brain atlas (20). All MR spectra were acquired using a single-voxel, ultra-short echo-time stimulated echo acquisition mode pulse sequence, with $\mathrm{TR}=3,000 \mathrm{msec}$ and $\mathrm{TE}=2.35 \mathrm{msec}$. The total number of acquisitions was 256 . The $3 \times 3 \times 3 \mathrm{~mm}^{3} \mathrm{VOI}$ primarily contained the right dorsal hippocampus in addition to some adjacent tissue. Outer volume suppression was performed around the VOI to inhibit any non-hippocampal contaminant signals. Automated shimming was performed for the VOI to yield a water spectrum width of 15-20 Hz. The B0 field was shimmed using a 3D gradient shimming method. Shortly afterwards, a manual shim based on second-order 3D gradient shimming was adopted to reduce any signal in homogeneities in the B0 field. Localized voxel shimming was performed using the FASTMAP technique prior to spectral acquisition (21). Outer volume suppression and water suppression with variable pulse power and optimized relaxation delays were used to acquire proton spectra. In order to correct for small variations in coil sensitivity, the unsuppressed water signal from the prescribed voxel was used as a reference (22). The total scan duration of one MRS measurement was $13 \mathrm{~min}$ and $54 \mathrm{sec}$. The raw spectral data were exported to an external VnmrJ v4.0 workstation (Agilent Technologies, Inc.) for post-processing.

MRS data processing and analysis. The MRS-based quantification of metabolite concentrations was performed using LCModel software (version 6.2-4E; LCModel Inc., Oakville, ON, Canada) (23). The raw data were processed using LCModel. Quantitative metabolite concentrations were obtained from the raw data following processing using LCModel and scaled to the water signal. The quantitative analysis algorithm of LCModel, which is based on linear combinations, was used to calculate the optimal fitting of the objective spectra to the model spectra. The tissue water concentration was used as the internal standard. Only spectra with a full width at half maximum $<20$, metabolite concentration fitting results with Cramer-Rao lower bound $<20 \%$ (24) and a signal-to-noise ratio $\geq 10$ were used for data analysis.

The base set included the following 17 metabolites: Alanine, aspartate, Cr,GABA, glucose, Glu, glutamine (Gln), glutathione, glycerophosphorylcholine (GPC), lactate, myo-inositol (mI), $\mathrm{N}$-acetyl-L-aspartate (NAA), N-acetylaspartylglutamate (NAAG), phosphorylcholine (PCh), phosphocreatine (PCr), scyllo-inositol and taurine (Tau). The signal intensities were processed with water scaling for absolute quantification of the metabolic concentrations. Additionally, the sums of certain metabolites, including NAA+NAAG, $\mathrm{Cr}+\mathrm{PCr}$, Glu+Gln and $\mathrm{GPC}+\mathrm{PCh}$, were measured.

Preparation of tissue samples for HPLC analysis. The right hippocampus was homogenized $(10 \% \mathrm{w} / \mathrm{v})$ in ice-cold phosphate buffer solution (0.1 M; pH 7.2; Yuanye Biotechnology, Co., Ltd.). The homogenate was centrifuged at $12,000 \mathrm{x} \mathrm{g}$ for $20 \mathrm{~min}$ at $4^{\circ} \mathrm{C}$. The supernatant was mixed with an equivalent volume of methanol for overnight protein precipitation at $4^{\circ} \mathrm{C}$, and the resulting samples were frozen at $-80^{\circ} \mathrm{C}$ following membrane filtration.

Quantification of GABA and Glu in vitro. The HPLC procedure was performed according to a previously described method (25). Liquid chromatography was performed using an Agilent 1100 HPLC system (Agilent Technologies, Inc.). In order to detect the concentrations of GABA and Glu, a standard curve was obtained for each under standard chromatographic conditions, with concentration as the horizontal axis and the product peak area as the vertical axis. Chromatographic separation was obtained on a phase column with an Agilent C18 guard column (250x4.6 mm²; $5 \mu \mathrm{m}$; Agilent Technologies, Inc.). The temperature of the column was maintained at $25^{\circ} \mathrm{C}$. The mobile phase consisted of a mixture of $0.1 \mathrm{~mol} / 1$ sodium acetate $(\mathrm{pH}$ 6.8 with $2 \%$ tetrahydrofuran), methanol and water at a flow rate of $0.75 \mathrm{ml} / \mathrm{min}$. The GABA and Glu levels were determined using a scanning fluorescence detector with the excitation and emission wavelengths set at $338 \mathrm{~nm}$ and $425 \mathrm{~nm}$, respectively. The standard lines of GABA and Glu were $\mathrm{y}_{\mathrm{GABA}}=9.94 \mathrm{x}+54.24$ $\left(\mathrm{R}^{2}=0.99\right)$ and $\mathrm{y}_{\mathrm{Glu}}=12.06 \mathrm{x}+122.2\left(\mathrm{R}^{2}=0.99\right)$ The HPLC system was connected to a computer to quantify the mixture of GABA and Glu by comparing the area under each peak with the corresponding measure of each reference standard, using the Agilent chemical workstation software (ChemStation for LC 3D, Rev. A.10.01; Agilent Technologies, Inc.). The $\mathrm{Cu}$ concentration in the brain tissue of the rats was not measured in the present study since Zhang et al (26) demonstrated that intranasal delivery of $\mathrm{Cu}$ nanoparticles at 1 and $10 \mathrm{mg} / \mathrm{kg}$ for 15 days did not change the $\mathrm{Cu}$ concentration in different tissues, including liver, lung, spleen, kidney and brain, in mice.

Statistical analysis. All data are expressed as the mean \pm standard deviation. Statistical analysis was performed using SPSS software (version 16.0; SPSS, Inc., Chicago, IL, USA), and $\mathrm{P}<0.05$ was considered to indicate a statistically significant difference. For the behavioural tests, the escape latency in the MWM test was analysed by repeated measures generalised linear model and multivariate analysis of variance (ANOVA) procedures, and one-way ANOVA with a Fisher's least significant difference post hoc test was performed for the other data. For the ${ }^{1} \mathrm{H}-\mathrm{MRS}$ and HPLC brain metabolite data, the normality and homogeneity of the data were verified. The data were statistically analysed by one-way ANOVA as long as they satisfied the normality and homogeneity assumptions; 


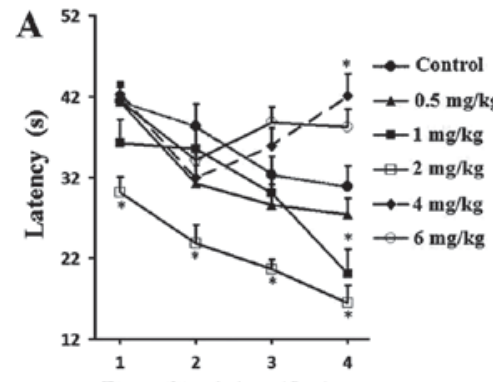

Day of training (day)

D

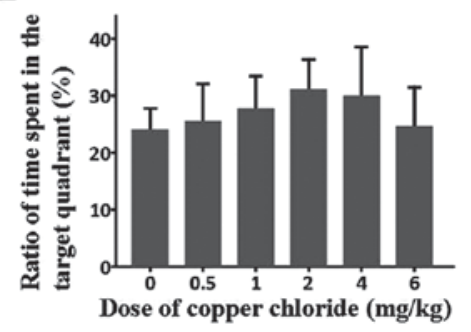

B

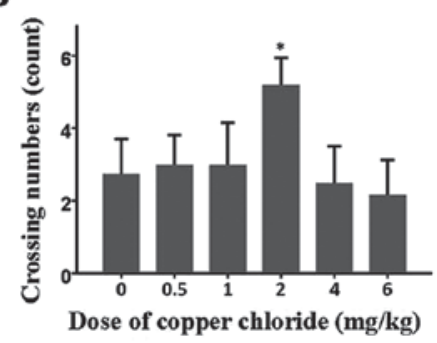

E

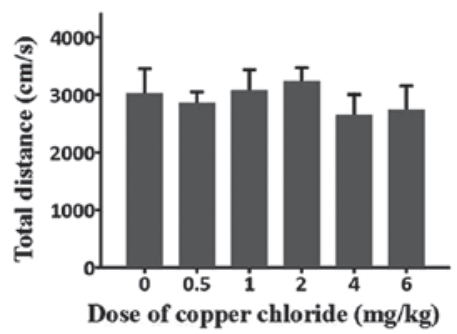

C

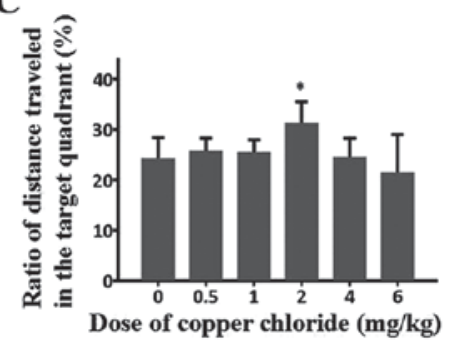

F

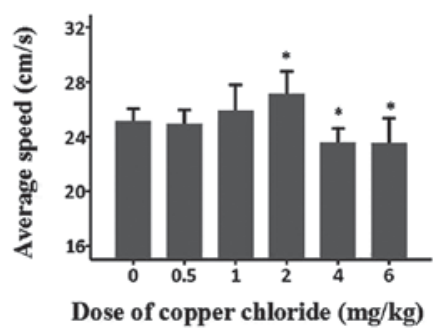

Figure 1. Copper chloride dose-dependently affects the spatial learning and memory of rats. (A) At $2.0 \mathrm{mg} / \mathrm{kg}$, CuCl${ }_{2}$ facilitated the learning process of rats during the training trials of the Morris water maze test, whereas 4.0 and $6.0 \mathrm{mg} / \mathrm{kg} \mathrm{CuCl}{ }_{2}$ exerted adverse effects. (B) $\mathrm{Rats}$ given $2.0 \mathrm{mg} / \mathrm{kg} \mathrm{CuCl}{ }_{2}$ visited the

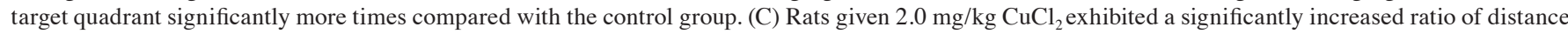
travelled in the target quadrant over the total distance in the water maze compared with the control rats. (D) $\mathrm{Rats}$ given $2 \mathrm{mg} / \mathrm{kg} \mathrm{CuCl} \mathrm{l}_{2}$ exhibited an increased ratio of time spent in the target quadrant, while the higher dose group (6.0 mg/kg) exhibited an adverse effect. (E) The total travelled distance of the rats in all

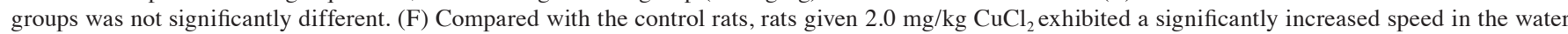
maze, while those given $6.0 \mathrm{mg} / \mathrm{kg} \mathrm{CuCl}_{2}$ travelled more slowly. The data are presented as the mean \pm standard deviation. ${ }^{*} \mathrm{P}<0.05 \mathrm{vs}$. control $(1.0 \mathrm{ml} / \mathrm{kg}$ of sterilized saline with $0 \mathrm{mg} / \mathrm{kg}$ copper chloride).

otherwise, Mann-Whitney and Kruskal-Wallis non-parametric tests were performed. Correlations between the brain metabolite concentrations detected through ${ }^{1} \mathrm{H}-\mathrm{MRS}$ and HPLC, and the behavioural test results, were investigated using Pearson and Spearman tests.

\section{Results}

Behavioural test. In order to examine the effects of exogenous $\mathrm{Cu}$ exposure on the spatial learning and memory of S-D rats, the MWM test was performed with subjects that were intraperitoneally injected with various doses of $\mathrm{CuCl}_{2}(0,0.5$, $1.0,2.0,4.0$ and $6.0 \mathrm{mg} / \mathrm{kg})$. Overall, there was a significant effect of day and latency $\left(\mathrm{F}_{(3,236)}=8.28 ; \mathrm{P}<0.01\right)$, and an interaction between day and group was observed $\left(\mathrm{F}_{(5,234)}=14.49\right.$; $\mathrm{P}<0.01)$. During the training phase, on the first day, all groups spent a comparable amount of time finding the submerged platform, except for the group treated with $2.0 \mathrm{mg} / \mathrm{kg} \mathrm{CuCl}$; this group spent less time finding the platform $(\mathrm{P}=0.002)$. On the following 3 days, the rats treated with 4.0 and $6.0 \mathrm{mg} / \mathrm{kg}$ $\mathrm{CuCl}_{2}$ exhibited no progress in the learning phase in terms of the time spent finding the platform; by contrast, all of the other groups exhibited typical progress in the water maze test, as they spent less and less time finding the platform (Fig. 1A). During the probe test, the performance of the 0.5 and $1.0 \mathrm{mg} / \mathrm{kg}$ groups was comparable with that of the control group, although the $2.0 \mathrm{mg} / \mathrm{kg}$ group crossed the target quadrant more frequently than the control group $(\mathrm{P}<0.05)$. By contrast, the 4.0 and $6.0 \mathrm{mg} / \mathrm{kg}$ groups visited the target quadrant markedly fewer times (Fig. 1B). These results indicated deficient memory retrieval in the groups that received higher doses and a potential beneficial effect on memory retrieval in the $2.0 \mathrm{mg} / \mathrm{kg} \mathrm{CuCl}{ }_{2}$ group. The ratios of distance travelled in the target quadrant (Fig. 1C), the ratios of time spent in the target quadrant (Fig. 1D), the total distance (Fig. 1E) and the average speed data (Fig. 1F) additionally suggested an adverse or beneficial effect of the different doses of $\mathrm{CuCl}_{2}$ on the MWM performance of the various groups.

${ }^{1} H$-MRS analysis. The ${ }^{1} \mathrm{H}-\mathrm{MRS}$ analysis was performed subsequent to the MWM test. A $3 \times 3 \times 3 \mathrm{~mm}^{3}$ VOI was positioned in the right side of the dorsal hippocampus of the rat, as presented in the localization images (Fig. 2A). Representative spectra acquired from this VOI in each group are presented in Fig. 2B. The absolute concentrations of brain metabolites, including $\mathrm{Cr}, \mathrm{PCr}, \mathrm{Cr}+\mathrm{PCr}$, GABA, Glu, Gln, Glu+Gln, NAA, NAAG, $\mathrm{GPC}+\mathrm{PCh}, \mathrm{mI}$ and Tau, were calculated using LCModel. For $\mathrm{Cr}$, all rats exposed to $\mathrm{CuCl}_{2}$ were observed to have levels comparable to those of the control group. In terms of $\mathrm{PCr}$, no difference was noted between the control group and any other group, except for the $2.0 \mathrm{mg} / \mathrm{kg}$ group, which exhibited a significantly increased level $(\mathrm{P}<0.01)$. Therefore, $\mathrm{Cr}+\mathrm{PCr}$ levels exhibited the same pattern as PCr levels. The effects of $\mathrm{CuCl}_{2}$ on the levels of NAA and NAA+NAAG exhibited typical bell-shaped curves; significantly increased levels of NAA were observed only in the $2.0 \mathrm{mg} / \mathrm{kg}$ group $(\mathrm{P}=0.018)$, while NAA+NAAG levels were increased in the 1.0 and $2.0 \mathrm{mg} / \mathrm{kg}$ groups $(\mathrm{P}=0.011$ and $\mathrm{P}=0.01$, respectively). The $\mathrm{CuCl}_{2}$-induced alterations in GABA, Glu, Gln, and Glu+Gln produced similar bell curves, although the alterations were not significant. No differences in $\mathrm{mI}$ and GPC $+\mathrm{PCh}$ levels were observed between the control group and any other group. The 
A

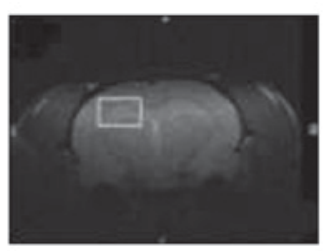

B
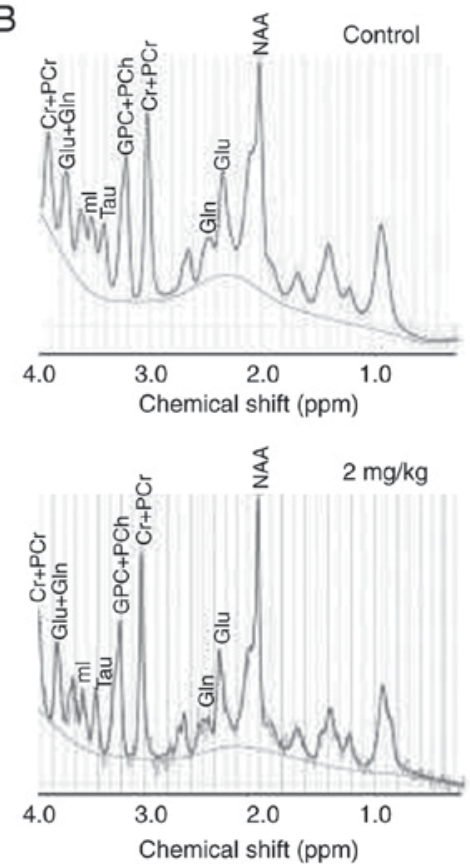
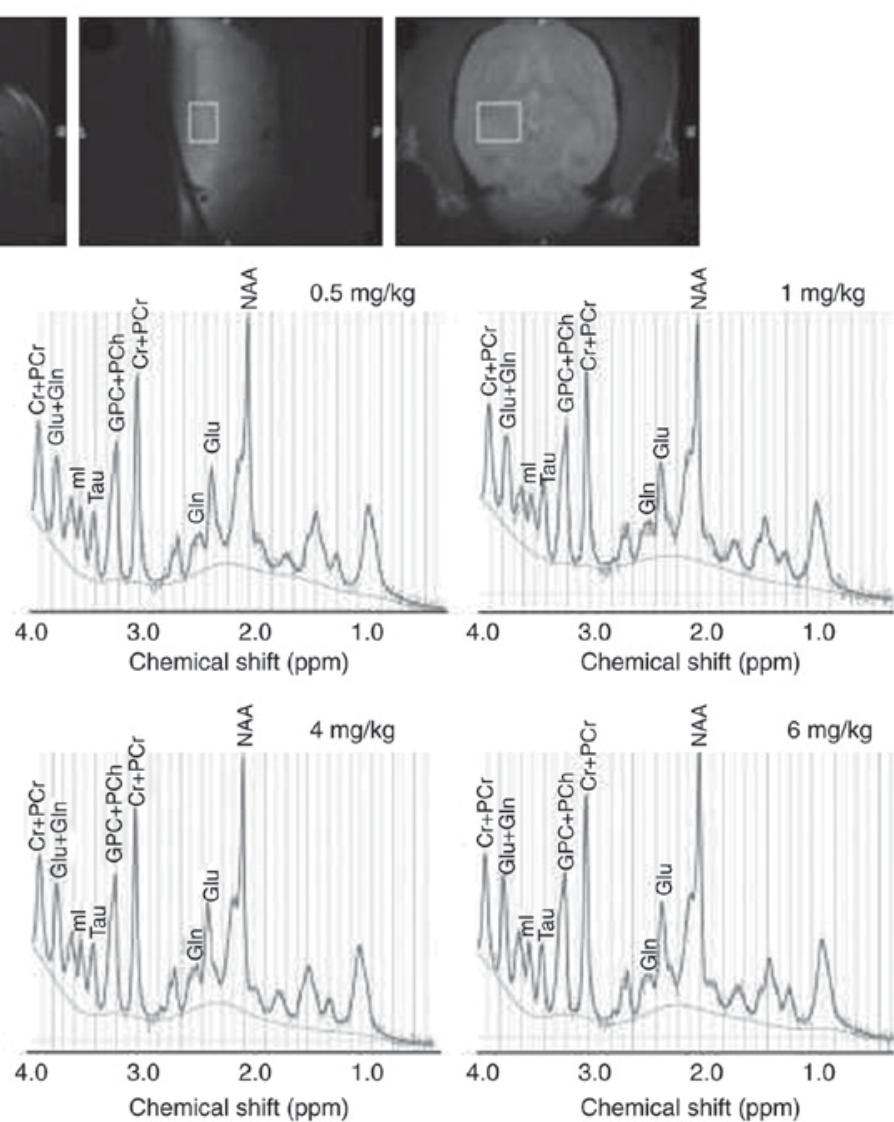

Figure 2. Location of the VOI and representative ${ }^{1} \mathrm{H}-\mathrm{MRS}$ spectra for all groups. (A) The VOI was located in the right dorsal hippocampus of the rats, in the coronal, saggital and axial directions. (B) Representative ${ }^{1} \mathrm{H}-\mathrm{MRS}$ spectra obtained from the control and 0.5, 1.0, 2.0, 4.0 and 6.0 mg/kg CuCl ${ }_{2}$ exposure groups. Cr, creatine; PCr, phosphocreatine; Glu, glutamate; Gln, glutamine; mI, myo-inositol; Tau, taurine; PCh, phosphorylcholine; NAA, N-acetylaspartate; VOI, volume of interest; ${ }^{1} \mathrm{H}-\mathrm{MRS}$, proton magnetic resonance spectroscopy.

only significant difference in Tau levels was observed between the $2.0 \mathrm{mg} / \mathrm{kg}$ and control groups $(\mathrm{P}=0.021$; Table I).

HPLC analysis. HPLC analysis, which may avoid certain confounding factors that may affect ${ }^{1} \mathrm{H}-\mathrm{MRS}$, including breathing, inhomogeneity of the B0 field and volume contamination, was performed to further evaluate the levels of two neurotransmitters, GABA and Glu, which were of interest. The absolute concentrations of these two neurotransmitters were determined subsequent to a standard curve being obtained for each. GABA and Glu peaks for a standard sample and a typical base peak chromatogram obtained for a hippocampus sample from a control rat are presented in Fig. 3. Similar to the ${ }^{1} \mathrm{H}-\mathrm{MRS}$ results, the effects of $\mathrm{CuCl}_{2}$ on GABA and Glu levels were shaped like bell curves. The highest GABA level was observed in the $2.0 \mathrm{mg} / \mathrm{kg}$ group, while comparable, although decreased, levels were observed in the other groups $(\mathrm{P}=0.028)$. However, the bell curve of the effect on Glu levels was unique. The curve increased until it reached the highest level for the $2.0 \mathrm{mg} / \mathrm{kg}$ group and subsequently declined $(\mathrm{P}=0.039)$. A remarkable decrease was observed for the 4.0 and $6.0 \mathrm{mg} / \mathrm{kg}$ groups $(\mathrm{P}=0.042$ and $\mathrm{P}<0.01)$ compared with the control group (Table II).

Positive correlations between spatial memory and levels of Glu and NAA. In order to examine the association between the $\mathrm{CuCl}_{2}$-induced effects on spatial memory and metabolite concentrations detected by ${ }^{1} \mathrm{H}-\mathrm{MRS}$ and HPLC, the correlation between metabolite concentrations and crossing numbers was analysed using Pearson and Spearman correlation tests. This analysis revealed that the number of platform crossings on probe trials was positively correlated with the hippocampal levels of Glu ( $\mathrm{r}=0.512$; $\mathrm{P}=0.002$; Fig. 4A) and NAA $(\mathrm{r}=0.69$; $\mathrm{P}<0.001$; Fig. 4B) detected by ${ }^{1} \mathrm{H}-\mathrm{MRS}$. In accordance with the ${ }^{1} \mathrm{H}-\mathrm{MRS}$ results, a similar positive correlation was identified between the number of crossings and the Glu levels revealed by HPLC analysis ( $\mathrm{r}=0.433$; $\mathrm{P}=0.002$; Fig. 4C).

\section{Discussion}

An increasing number of studies have reported on the effects of chronic $\mathrm{Cu}$ exposure on brain functions. However, the reported results have been inconsistent; $\mathrm{Cu}$ excess and deficiency have been demonstrated to impair the spatial memory capacity of the brain. For example, chronic exposure to $\mathrm{Cu}$ in drinking water has been demonstrated to impair spatial memory in mice (27), and chronic $\mathrm{Cu}$ exposure has been additionally observed to accelerate memory impairment in 3xTg-AD mice (28). In another study, compared with control rats, $\mathrm{Cu}$-administered animals exhibited impaired spatial memory in addition to significantly decreased serum acetylcholinesterase activity (29). However, Cu deficiency is detrimental to the development of brain function. In support of this hypothesis, following water-mediated $\mathrm{Zn}$ supplementation for 4 months, 
Table I. Brain metabolite concentrations determined by in vivo proton magnetic resonance spectroscopy in hippocampal tissue $(\mathrm{mmol} / \mathrm{l})$.

\begin{tabular}{|c|c|c|c|c|c|c|}
\hline Metabolite & Control & $\begin{array}{c}\mathrm{CuCl}_{2} \\
(0.5 \mathrm{mg} / \mathrm{kg})\end{array}$ & $\begin{array}{c}\mathrm{CuCl}_{2} \\
(1.0 \mathrm{mg} / \mathrm{kg})\end{array}$ & $\begin{array}{c}\mathrm{CuCl}_{2} \\
(2.0 \mathrm{mg} / \mathrm{kg})\end{array}$ & $\begin{array}{c}\mathrm{CuCl}_{2} \\
(4.0 \mathrm{mg} / \mathrm{kg})\end{array}$ & $\begin{array}{c}\mathrm{CuCl}_{2} \\
(6.0 \mathrm{mg} / \mathrm{kg})\end{array}$ \\
\hline $\mathrm{Cr}$ & $2.91 \pm 0.15$ & $2.80 \pm 0.24$ & $2.84 \pm 0.15$ & $2.61 \pm 0.06$ & $2.67 \pm 0.49$ & $2.56 \pm 0.12$ \\
\hline $\mathrm{PCr}$ & $3.30 \pm 0.28$ & $3.35 \pm 0.76$ & $3.44 \pm 0.22$ & $4.37 \pm 0.57^{\mathrm{b}}$ & $3.28 \pm 0.20$ & $3.23 \pm 0.35$ \\
\hline $\mathrm{Cr}+\mathrm{PCr}$ & $5.65 \pm 0.50$ & $5.87 \pm 0.76$ & $6.12 \pm 0.24$ & $6.73 \pm 0.27^{\mathrm{b}}$ & $5.54 \pm 0.17$ & $5.51 \pm 0.47$ \\
\hline NAA & $5.70 \pm 0.61$ & $5.85 \pm 0.96$ & $6.27 \pm 0.43$ & $6.63 \pm 0.20^{\mathrm{a}}$ & $6.18 \pm 0.44$ & $5.80 \pm 0.64$ \\
\hline $\mathrm{NAA}+\mathrm{NAAG}$ & $6.45 \pm 0.62$ & $6.57 \pm 0.99$ & $7.13 \pm 0.44^{\mathrm{a}}$ & $7.49 \pm 0.51^{\mathrm{b}}$ & $6.71 \pm 0.28$ & $6.29 \pm 0.33$ \\
\hline GABA & $1.63 \pm 0.39$ & $1.65 \pm 0.23$ & $1.64 \pm 0.19$ & $1.66 \pm 0.27$ & $1.60 \pm 0.20$ & $1.54 \pm 0.22$ \\
\hline Glu & $7.22 \pm 0.40$ & $7.41 \pm 0.31$ & $7.46 \pm 0.55$ & $7.57 \pm 0.76$ & $7.20 \pm 0.49$ & $7.15 \pm 0.05$ \\
\hline Gln & $1.74 \pm 0.34$ & $1.82 \pm 0.28$ & $1.95 \pm 0.35$ & $1.93 \pm 0.62$ & $1.71 \pm 0.22$ & $1.74 \pm 0.36$ \\
\hline Glu+Gln & $8.90 \pm 0.61$ & $9.12 \pm 0.15$ & $9.49 \pm 0.87$ & $9.63 \pm 1.19$ & $8.81 \pm 0.40$ & $8.79 \pm 0.25$ \\
\hline $\mathrm{GPC}+\mathrm{PCh}$ & $1.31 \pm 0.09$ & $1.21 \pm 0.20$ & $1.35 \pm 0.11$ & $1.27 \pm 0.17$ & $1.27 \pm 0.20$ & $1.43 \pm 0.10$ \\
\hline $\mathrm{mI}$ & $4.22 \pm 0.68$ & $4.33 \pm 0.87$ & $4.51 \pm 0.28$ & $4.65 \pm 0.28$ & $4.34 \pm 0.46$ & $3.99 \pm 0.38$ \\
\hline Tau & $3.97 \pm 0.43$ & $4.09 \pm 0.65$ & $4.41 \pm 0.45$ & $4.65 \pm 0.32^{\mathrm{a}}$ & $4.23 \pm 0.43$ & $4.35 \pm 0.62$ \\
\hline
\end{tabular}

All data are expressed as the mean \pm standard deviation. ${ }^{\mathrm{a}} \mathrm{P}<0.05$, ${ }^{\mathrm{b}} \mathrm{P}<0.01$ vs. control. Cr, creatine; PCr, phosphocreatine; Glu, glutamate; Gln, glutamine; Tau, taurine; PCh, phosphorylcholine; NAA, N-acetylaspartate; NAAG, N-acetylaspartylglutamate; GABA, $\gamma$-aminobutyric acid; PCh, phosphorylcholine; GPC, glycerophosphorylcholine; mI, myo-inositol.
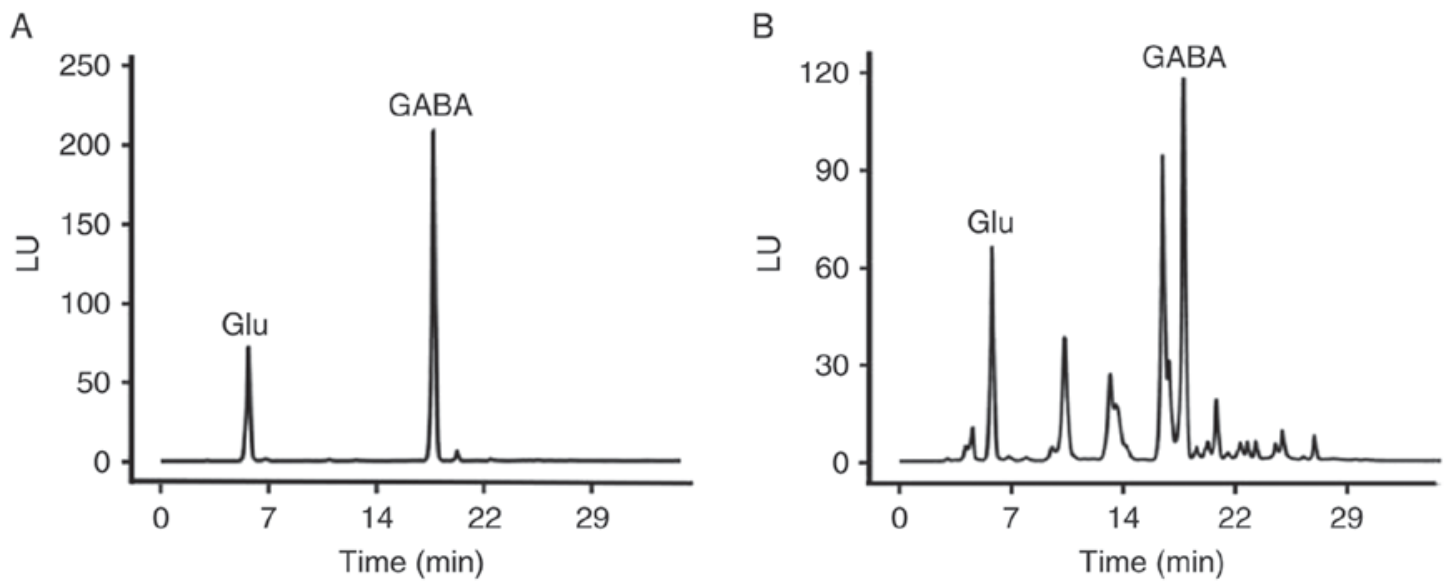

Figure 3. Standards and a representative high-performance liquid chromatography spectrum. (A) GABA and Glu peaks for a standard sample. (B) A typical base peak chromatogram obtained for a hippocampal sample from a control rat. GABA, $\gamma$-aminobutyric acid; Glu, glutamate.

S-D rats exhibited significantly increased levels of anxiety compared with controls raised on lab water. The Zn-treated rats took a markedly longer time to reach the platform in the MWM, suggesting a spatial memory deficiency. These behavioural changes are thought to be relevant to $\mathrm{Cu}$ deficiency as the addition of $\mathrm{Cu}$ to the $\mathrm{Zn}$-supplemented water returned freezing and latency values closer to those of controls (30). The authors additionally examined the effect of increasing $\mathrm{Zn}$ levels in the drinking water in $\mathrm{Tg} 2576$ mice. Compared with mice raised on lab water, the $\mathrm{Zn}$-supplemented mice exhibited a significant increase in latency and fewer platform crossings on probe trials in the MWM test. However, no significant differences were observed between the $\mathrm{Zn}+\mathrm{Cu}$ group and the group raised on lab water. The authors suggested that the negative consequences of $\mathrm{Zn}$ may result in reduced $\mathrm{Cu}$ levels and that the effects may be due to an imbalance of these metal ions, rather than a direct effect of increased Zn (31). Similarly, a recent in vitro study observed biphasic effects of $\mathrm{Cu}$ on rat learning and memory in the MWM test. Free hippocampal $\mathrm{Cu}$ was demonstrated to increase at a lower concentration of $\mathrm{Cu}$ (II) acetate $\left[\mathrm{Cu}(\mathrm{OAc})_{2}\right](0.2 \mathrm{mg} / \mathrm{kg})$, which improved learning and memory. However, increased doses of $\mathrm{Cu}$ decreased superoxide dismutase-1 (SOD1) activity, increased malondialdehyde (MDA) levels and impaired spatial cognition (32).

Dysregulation of $\mathrm{Cu}$ metabolism contributes to an interruption of neuronal function, and further leads to neurodegeneration, necrosis and gliocyte hyperplasia (32). The effects of acute $\mathrm{Cu}$ exposure on the spatial learning and memory of rats in vivo were examined for the first time, to the best of our knowledge, in the present study. The following results were observed in the present study: i) 0.5 and $1.0 \mathrm{mg} / \mathrm{kg}$ $\mathrm{CuCl}_{2}$ exerted no effects; ii) $2.0 \mathrm{mg} / \mathrm{kg} \mathrm{CuCl}$ promoted the 
Table II. Concentrations of GABA and Glu detected by high-performance liquid chromatography (mmol/g).

\begin{tabular}{lcccccc}
\hline Metabolite & Control & $\begin{array}{c}\mathrm{CuCl}_{2} \\
(0.5 \mathrm{mg} / \mathrm{kg})\end{array}$ & $\begin{array}{c}\mathrm{CuCl}_{2} \\
(1.0 \mathrm{mg} / \mathrm{kg})\end{array}$ & $\begin{array}{c}\mathrm{CuCl}_{2} \\
(2.0 \mathrm{mg} / \mathrm{kg})\end{array}$ & $\begin{array}{c}\mathrm{CuCl}_{2} \\
(4.0 \mathrm{mg} / \mathrm{kg})\end{array}$ & $\begin{array}{c}\mathrm{CuCl}_{2} \\
(6.0 \mathrm{mg} / \mathrm{kg})\end{array}$ \\
\hline GABA & $2.83 \pm 0.17$ & $3.01 \pm 0.34$ & $3.35 \pm 0.39$ & $3.53 \pm 0.83^{\mathrm{b}}$ & $2.97 \pm 0.34$ & $2.75 \pm 0.57$ \\
Glu & $6.00 \pm 0.48$ & $6.14 \pm 0.56$ & $6.31 \pm 0.75$ & $6.63 \pm 0.74^{\mathrm{a}}$ & $5.42 \pm 0.72^{\mathrm{a}}$ & $4.08 \pm 0.53^{\mathrm{b}}$ \\
\hline
\end{tabular}

All data are expressed as the mean \pm standard deviation. ${ }^{\mathrm{a}} \mathrm{P}<0.05,{ }^{\mathrm{b}} \mathrm{P}<0.01 \mathrm{vs}$. control. GABA, $\gamma$-aminobutyric acid; Glu, glutamate.
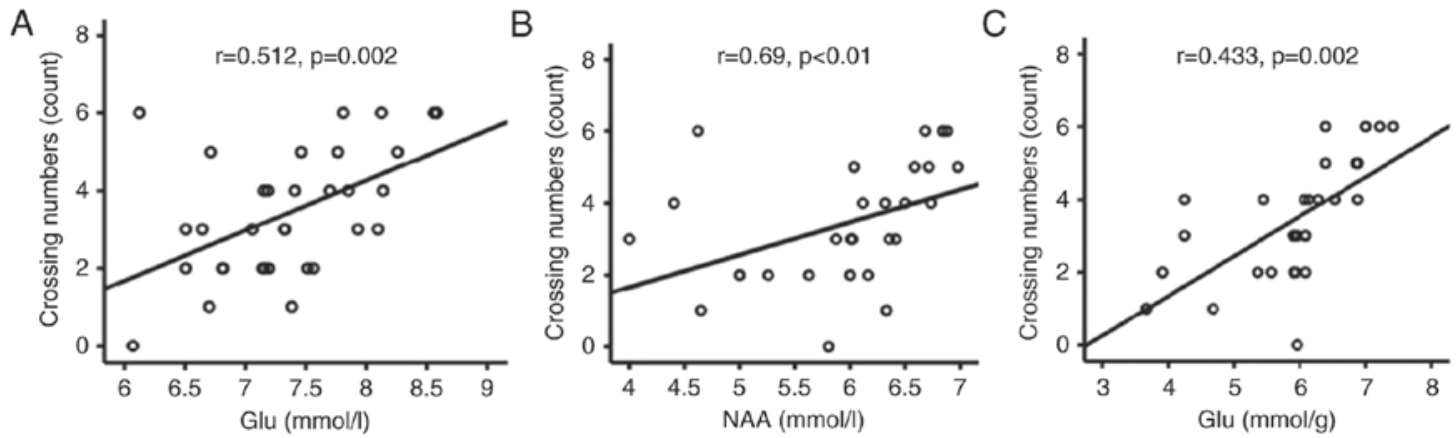

Figure 4. Positive correlations between spatial memory, and Glu and NAA levels. (A) The correlation between Glu concentrations (detected by proton magnetic resonance spectroscopy) in the hippocampus and the number of crossings of the target quadrant in the water maze. (B) The correlation between NAA concentrations in the hippocampus and the number of crossings of the target quadrant in the water maze. (C) The correlation between Glu concentrations (detected by high-performance liquid chromatography) in the hippocampus and the number of crossings of the target quadrant in the water maze. Glu, glutamate; NAA, $\mathrm{N}$-acetyl-L-aspartate.

learning process in the training phase of the MWM test and benefited spatial learning and memory in the probe test; and iii) 4.0 and $6.0 \mathrm{mg} / \mathrm{kg} \mathrm{CuCl}_{2}$ impaired the learning process and the spatial memory of the subjects. These findings suggested that the spatial learning and memory functions of the brain may tolerate $\mathrm{Cu}$ exposure. In support of this hypothesis, a previous animal study demonstrated that $\mathrm{Cu}$ suppressed hippocampal long-term potentiation in rats, although it did not alter learning or memory in the MWM test (33). In a mouse study, intranasal administration of $\mathrm{Cu}$ nanoparticles at 1 and $10 \mathrm{mg} / \mathrm{kg}$ for 15 days did not alter the $\mathrm{Cu}$ concentrations in various tissues, including the liver, lung, spleen, kidney and brain, indicating that the animals were capable of removing or metabolizing the inhaled $\mathrm{Cu}$ nanoparticles (26). Although the $\mathrm{CuCl}_{2}$ was intraperitoneally injected in the present study, the three lower doses $(0.5,1.0$ and $2.0 \mathrm{mg} / \mathrm{kg})$ were unlikely to be toxic to brain cells, based on the results of the studies referred to above. Additionally, $2.0 \mathrm{mg} / \mathrm{kg} \mathrm{CuCl} \mathrm{Cu}_{2}$ exerted a beneficial effect on the learning and spatial memory of the rats. The beneficial effect that was observed in the $2.0 \mathrm{mg} / \mathrm{kg}$ group is unlikely to be an artificial phenomenon, considering that the rats which received this dose of $\mathrm{CuCl}_{2}$ performed better than all of the other groups in the training phase and probe test. The increased travel speed of the $2.0 \mathrm{mg} / \mathrm{kg}$ group during the test period of the water maze additionally indicates that the rats in this group were more energetic than the rats in the other groups. This energy may have contributed to the improved performance of these rats on the other indexes. The spatial memory impairments of the rats treated with $6.0 \mathrm{mg} / \mathrm{kg}$ $\mathrm{CuCl}_{2}$ are consistent with the excess $\mathrm{Cu}$-mediated cognitive function deficiency reported in previous animal studies. The result was correspondent with a previous in vitro study, which demonstrated that low concentrations of $\mathrm{Cu}$ (II) (1-100 nM) improved neuronal firing rate, although higher concentrations (1-5 $\mu \mathrm{M})$ reduced the firing rate (32). It may be hypothesised that increased doses of $\mathrm{CuCl}_{2}$ may decrease the activity of SOD1 and the levels of MDA, and impair spatial cognition. However, lower doses of $\mathrm{CuCl}_{2}$ may have the opposite effect.

The second significant finding of the present study is that the effect of $\mathrm{CuCl}_{2}$ on $\mathrm{PCr}, \mathrm{Cr}+\mathrm{PCr}$, NAA and NAA+NAAG levels exhibited a typical bell curve, with a significantly increased level in the $2.0 \mathrm{mg} / \mathrm{kg}$ group. All of these indexes are associated with mitochondrial function. The increased levels in the $2.0 \mathrm{mg} / \mathrm{kg}$ $\mathrm{CuCl}_{2}$ group suggested that this treatment had a beneficial effect on mitochondrial function; it may be suggested that this dose of $\mathrm{CuCl}_{2}$ enhanced mitochondrial function in neurons. This hypothesis may account for the increased energetic status of the $2.0 \mathrm{mg} / \mathrm{kg}$ group, as illustrated in the MWM test. Notably, NAA levels in the brain impact the viability of neurons and are additionally associated with neuronal-oligodendroglial integrity, which is necessary for the normal function of neuronal circuits in the brain. In this context, the increased NAA level in the $2.0 \mathrm{mg} / \mathrm{kg} \mathrm{CuCl}_{2}$ group may explain the improved performance of this group of rats in the MWM test. In support of this explanation, 8 weeks of social isolation decreased the NAA and $\mathrm{PCr}$ levels in the dorsal hippocampus of rats and impaired spatial working memory (34).

Glu, the main excitatory neurotransmitter in the CNS, is not only associated with cognitive and emotional activities; it is also an excitotoxin. An overdose of extracellular Glu may cause the excessive accumulation of neurons, leading to cell death, and ultimately to learning and memory impairment. Dysfunction of 
glutamatergic transmission is considered to be a predominant feature and fundamental pathological mechanism of neurodegenerative disorders that involve impaired spatial memory. Previous in vivo human ${ }^{1} \mathrm{H}-\mathrm{MRS}$ studies reported decreased Glu levels in the hippocampus of patients with neurodegenerative diseases (35). In the present study, the ${ }^{1} \mathrm{H}-\mathrm{MRS}$ results indicated a mild, although not statistically significant, increase in hippocampal Glu levels in rats that were exposed to $2.0 \mathrm{mg} / \mathrm{kg}$ $\mathrm{CuCl}_{2}$ compared with those in the control group. This increase was confirmed via HPLC analysis; in this analysis, the difference reached significance. By contrast, the two higher doses (4.0 and $6.0 \mathrm{mg} / \mathrm{kg}$ ) of $\mathrm{CuCl}_{2}$ significantly decreased the levels of Glu. In the present study, the potential mechanisms of the $\mathrm{Cu}$-induced changes in Glu levels were not studied. However, it may be hypothesised that the increase in Glu levels induced by treatment with $2.0 \mathrm{mg} / \mathrm{kg} \mathrm{CuCl}{ }_{2}$ may reflect a compensatory effect to counteract the blockade of certain receptors of this neurotransmitter. In line with this speculation, CNS neurons possess the machinery to take up $\mathrm{Cu}$ and to subsequently release it at the synaptic cleft (36), where it may modulate excitatory and inhibitory neurotransmission. Indeed, $\mathrm{Cu}$ blocks GABAergic and $\alpha$-amino-3-hydroxy-5-methyl-4-isoxazolepropionic acid (AMPA) ergic neurotransmission when it is acutely applied to cultured rat olfactory bulb neurons (13). Cu was demonstrated to inhibit AMPAergic neurotransmission in rat cortical neurons (15) and GABAergic neurotransmission in acutely isolated rat cerebellar Purkinje cells (37). However, the compensatory response may reach its upper limit and even break down when the dose of $\mathrm{CuCl}_{2}$ is increased, as observed in the rats that received 4.0 and $6.0 \mathrm{mg} / \mathrm{kg} \mathrm{CuCl}$ in the present study. In agreement with this interpretation, glutamic acid concentrations were decreased in certain brain regions, including the hippocampus, in mice that inhaled a high dose of $\mathrm{Cu}$ nanoparticles (38).

GABA is a principal inhibitory neurotransmitter in the CNS and is known to be associated with cognitive function (39). In a recent study, $\mathrm{Cu}$ was demonstrated to affect the holding current of neurons by affecting GABA-mediated signalling (40). In another study, extra-synaptic GABA receptors were observed to be susceptible to $\mathrm{Cu}$ modulation (41). In agreement with these previous studies, the results of the present study demonstrated that hippocampal GABA levels were increased in the group of rats treated with $2.0 \mathrm{mg} / \mathrm{kg} \mathrm{CuCl}$, while this treatment had a beneficial effect on the learning and spatial memory capacity of the subjects.

Notably, hippocampal Glu levels in the rats that received the various doses of $\mathrm{CuCl}_{2}$ were positively correlated with the frequency of platform crossings in the target quadrant, suggesting a beneficial effect of higher Glu levels on the retention of spatial reference memory. This suggestion appears to argue against the commonly accepted notion that increased Glu levels in the hippocampus impair spatial memory. In order to interpret this apparent conflict, the following points are of importance: i) The increase in Glu observed in the rats that were given $2.0 \mathrm{mg} / \mathrm{kg}$ $\mathrm{CuCl}_{2}$ was mild (approximately 10\% higher compared with the level in the normal controls); ii) this mild increase reflected a compensatory response of hippocampal neurons to the blockade of AMPAergic neurotransmission, suggesting that the increase was unlikely to be toxic to the neurons, as mentioned above; and iii) the $2.0 \mathrm{mg} / \mathrm{kg}$ dose of $\mathrm{CuCl}_{2}$ is relatively low and within the safe range for rats, as discussed above. In line with this claim, the
WHO Provisional Maximum Tolerable Daily Intake upper limit for $\mathrm{Cu}$ was set to $0.5 \mathrm{mg} / \mathrm{kg}$ per day (42), based on the fact that $\mathrm{Cu}$ does not appear to be a cumulative toxic hazard for humans (International Programme on Chemical Safety, 1982) $(43,44)$. In addition, in previous in vivo studies, a suspension of $\mathrm{Cu}$ nanoparticles was administered to animals at a dose of $30 \mathrm{mg} / \mathrm{kg}$ body weight, or at an even higher dose of $200 \mathrm{mg} / \mathrm{kg}$ to study the adverse effect of $\mathrm{Cu}$ nanoparticles $(45,46)$. In a previous study, $\mathrm{S}-\mathrm{D}$ rats were given once-daily intraperitoneal injections of $\mathrm{Cu}(\mathrm{OAc})_{2}$ at doses of $0.2,2$, or $20 \mathrm{mg} / \mathrm{kg}$ for 5 days to examine the effects of hippocampal $\mathrm{Cu}$ concentration on learning and memory and observed biphasic dose-dependent effects of $\mathrm{Cu}$ on rat learning and memory (32). Considering all these factors, it is plausible to conclude that the $2.0 \mathrm{mg} / \mathrm{kg}$ dose of $\mathrm{CuCl}_{2}$ that was administered to rats according to the procedure of the present study induced a mild increase in hippocampal Glu levels, and thus facilitated spatial learning and memory. In support of the beneficial effect of this dose of $\mathrm{CuCl}_{2}$, hippocampal NAA levels were positively correlated with the number of times the rats crossed the target quadrant in the water maze.

Notably, the region of interest in the ${ }^{1} \mathrm{H}-\mathrm{MRS}$ analysis was located in the right dorsal hippocampus of the rats, whereas the HPLC analysis measured metabolite levels in homogenates of the whole right hippocampus. In addition, ${ }^{1} \mathrm{H}-\mathrm{MRS}$ results may be affected by a number of confounding factors, including breathing, inhomogeneity of the B0 field and volume contamination, which may decrease the sensitivity of the analysis and increase the variance of measurements. Indeed, HPLC, although not ${ }^{1} \mathrm{H}-\mathrm{MRS}$, revealed significant alterations in GABA and Glu levels in the hippocampal tissue of the rats that were treated with 2.0 and $6.0 \mathrm{mg} / \mathrm{kg} \mathrm{CuCl}_{2}$.

In conclusion, the present study provided the first report, to the best of our knowledge, of a beneficial effect of $2.0 \mathrm{mg} / \mathrm{kg}$ $\mathrm{CuCl}_{2}$ on the spatial learning and memory of rats. The same treatment mildly increased $\mathrm{Glu}$, GABA, NAA, $\mathrm{PCr}$, and $\mathrm{Cr}+\mathrm{PCr}$ levels in the hippocampus. The concurrent mild increases in these brain metabolites in the hippocampus suggested that the administration of $\mathrm{CuCl}_{2}$ in accordance with the regimen used in the present study may cause a neurotrophin-like alteration. These results provided further evidence of the essential role of $\mathrm{Cu}$ in brain function.

\section{Acknowledgements}

The present study was funded in part by the Natural Science Foundation of Guangdong Province (grant no. 2016KZDXM013), National Science Foundation of China (grant no. 60971075) and the Scientific Research Foundation of Shantou University (grant no. NTF10010).

\section{References}

1. Cortese BM, Mitchell TR, Galloway MP, Prevost KE, Fang J, Moore GJ and Uhde TW: Region-specific alteration in brain glutamate: Possible relationship to risk-taking behavior. Physiol Behav 99: 445-450, 2010.

2. Prohaska JR: Role of copper transporters in copper homeostasis. Am J Clin Nutr 88 (Suppl): 826S-829S, 2008.

3. Squitti R, Lupoi D, Pasqualetti P, Dal Forno G, Vernieri F, Chiovenda P, Rossi L, Cortesi M, Cassetta E and Rossini PM: Elevation of serum copper levels in Alzheimer's disease. Neurology 59: 1153-1161, 2002. 
4. Squitti R, Pasqualetti P, Cassetta E, Dal Forno G, Cesaretti S, Pedace F, Finazzi-Agró A and Rossini PM: Elevation of serum copper levels discriminates Alzheimer's disease from vascular dementia. Neurology 60: 2013-2014, 2003.

5. Bush AI: Copper, zinc and the metallobiology of Alzheimer disease. Alzheimer Dis Assoc Disord 17: 147-150, 2003.

6. Brewer GJ: The risks of copper toxicity contributing to cognitive decline in the aging population and to Alzheimer's disease. J Am Coll Nutr 28, 238-242, 2009.

7. Pal A and Prasad R: Regional distribution of copper, zinc and iron in brain of Wistar rat model for non-Wilsonian brain copper toxicosis. Indian J Clin Biochem 31: 93-98, 2016.

8. Peters C, Muñoz B, Sepúlveda FJ, Urrutia J, Quiroz M, Luza S, De Ferrari GV, Aguayo LG and Opazo C: Biphasic effects of copper on neurotransmission in rat hippocampal neurons. J Neurochem 119: 78-88, 2011.

9. Maas JW and Colburn RW: Co-ordination chemistry and membrane function with particular reference to the synapse and catecholamine transport. Nature 208: 41-46, 1965.

10. Mercer JF: Menkes syndrome and animal models. Am J Clin Nutr 67 (Suppl): 1022S-1028S, 1998

11. Mathie A, Sutton GL, Clarke CE and Veale EL: Zinc and copper: Pharmacological probes and endogenous modulators of neuronal excitability. Pharmacol Ther 111: 567-583, 2006.

12. Salazar-Weber NL and Smith JP: Copper inhibits NMDA receptor-independent LTP and modulates the paired-pulse ratio after LTP in mouse Hippocampal slices. Int J Alzheimers Dis 2011: 864753, 2011.

13. Trombley PQ and Shepherd GM: Differential modulation by zinc and copper of amino acid receptors from rat olfactory bulb neurons. J Neurophysiol 76: 2536-2546, 1996.

14. Vlachová V, Zemková H and Vyklický L Jr: Copper modulation of NMDA responses in mouse and rat cultured hippocampal neurons. Eur J Neurosci 8: 2257-2264, 1996.

15. Weiser T and Wienrich M: The effects of copper ions on glutamate receptors in cultured rat cortical neurons. Brain Res 742 : 211-218, 1996.

16. Schlief ML and Gitlin JD: Copper homeostasis in the CNS: A novel link between the NMDA receptor and copper homeostasis in the hippocampus. Mol Neurobiol 33: 81-90, 2006.

17. Morris R: Developments of a water-maze procedure for studying spatial learning in the rat. J Neurosci Methods 11: 47-60, 1984.

18. Shi L, Adams MM, Long A, Carter CC, Bennett C, Sonntag WE, Nicolle MM, Robbins M, D'Agostino R and Brunso-Bechtold JK Spatial learning and memory deficits after whole-brain irradiation are associated with changes in NMDA receptor subunits in the hippocampus. Radiat Res 166: 892-899, 2006.

19. Shi L, Olson J, D'Agostino R Jr, Linville C, Nicolle MM, Robbins ME, Wheeler KT and Brunso-Bechtold JK: Aging masks detection of radiation-induced brain injury. Brain Res 1385: 307-316, 2011.

20. Witter MP and Amaral DG: Hippocampal formation, In: Paxinos G (ed.), The rat nervous system, 3rd edition. Academic Press, San Diego, pp637-703, 2004.

21. Gruetter R: Automatic, localized in vivo adjustment of all firstand second-order shim coils. Magn Reson Med 29: 804-811, 1993.

22. Harris JL, Yeh HW, Choi IY, Lee P, Berman NE, Swerdlow RH, Craciunas SC and Brooks WM: Altered neurochemical profile after traumatic brain injury: (1)H-MRS biomarkers of pathological mechanisms. J Cereb Blood Flow Metab 32: 2122-2134, 2012.

23. Provencher SW: Estimation of metabolite concentrations from localized in vivo proton NMR spectra. Magn Reson Med 30: 672-679, 1993

24. Cavassila S, Deval S, Huegen C, van Ormondt D and Graveron-Demilly D: Cramer-Rao bounds: An evaluation tool for quantitation. NMR Biomed 14: 278-283, 2001.

25. Zhu W, Masaki T, Cheung AK and Kern SE: In-vitro release of rapamycin from a thermosensitive polymer for the inhibition of vascular smooth muscle cell proliferation. J Bioequiv Availab 1: $3-12,2009$.

26. Zhang L, Bai R, Liu Y, Meng L, Li B, Wang L, Xu L, Le Guyader $L$ and Chen C: The dose-dependent toxicological effects and potential perturbation on the neurotransmitter secretion in brain following intranasal instillation of copper nanoparticles. Nanotoxicology 6: 562-575, 2012.
27. Ma Q, Ying M, Sui X, Zhang H, Huang H, Yang L, Huang X, Zhuang Z, Liu J and Yang X: Chronic copper exposure causes spatial memory impairment, selective loss of hippocampal synaptic proteins, and activation of PKR/eIF $2 \alpha$ pathway in mice. J Alzheimers Dis 43: 1413-1427, 2015.

28. Yu J, Luo X, Xu H, Ma Q, Yuan J, Li X, Chang RC, Qu Z, Huang $\mathrm{X}$, Zhuang $\mathrm{Z}$, et al: Identification of the key molecules involved in chronic copper exposure-aggravated memory impairment in transgenic mice of Alzheimer's disease using proteomic analysis. J Alzheimers Dis 44: 455-469, 2015.

29. Pal A, Badyal RK, Vasishta RK, Attri SV, Thapa BR and Prasad R: Biochemical, histological, and memory impairment effects of chronic copper toxicity: A model for non-Wilsonian brain copper toxicosis in Wistar rat. Biol Trace Elem Res 153: 257-268, 2013.

30. Railey AM, Micheli TL, Wanschura PB and Flinn JM: Alterations in fear response and spatial memory in pre- and post-natal zinc supplemented rats: Remediation by copper. Physiol Behav 100: 95-100, 2010

31. Railey AM, Groeber CM and Flinn JM: The effect of metals on spatial memory in a transgenic mouse model of Alzheimer's disease. J Alzheimers Dis 24: 375-381, 2011.

32. Zhang Y, Lu W, Han M, Li H, Luo H, Li W and Lin Z: Biphasic effects of copper on rat learning and memory in the morris water maze. Ann Clin Lab Sci 46: 346-352, 2016.

33. Leiva J, Palestini M, Infante C, Goldschmidt A and Motles E Copper suppresses hippocampus LTP in the rat, but does not alter learning or memory in the morris water maze. Brain Res 1256: 69-75, 2009.

34. Shao Y, Yan G, Xuan Y, Peng H, Huang QJ, Wu R and Xu H: Chronic social isolation decreases glutamate and glutamine levels and induces oxidative stress in the rat hippocampus. Behav Brain Res 282: 201-208, 2015.

35. Rupsingh R, Borrie M, Smith M, Wells JL and Bartha R: Reduced hippocampal glutamate in Alzheimer disease. Neurobiol Aging 32: 802-810, 2011.

36. Barnea A, Cho G and Hartter DE: A correlation between the ligand specificity for 67copper uptake and for copper-prostaglandin E2 stimulation of the release of gonadotropin-releasing hormone from median eminence explants. Endocrinology 122: $1505-1510,1988$

37. Sharonova IN, Vorobjev VS and Haas HL: High-affinity copper block of GABA(A) receptor-mediated currents in acutely isolated cerebellar Purkinje cells of the rat. Eur J Neurosci 10: 522-528, 1998.

38. Zhang L, Bai X, Tian H, Zhong L, Ma C, Zhou Y, Chen S and Li D: Synthesis of antibacterial film CTS/PVP/TiO2/Ag for drinking water system. Carbohydr Polym 89: 1060-1066, 2012.

39. Lanctôt KL, Herrmann N, Mazzotta P, Khan LR and Ingber N: GABAergic function in Alzheimer's disease: Evidence for dysfunction and potential as a therapeutic target for the treatment of behavioural and psychological symptoms of dementia. Can J Psychiatry 49: 439-453, 2004.

40. GaierED, Rodriguiz RM,Zhou J, Ralle M, Wetsel WC, Eipper BA and Mains RE: In vivo and in vitro analyses of amygdalar function reveal a role for copper. J Neurophysiol 111: 1927-1939, 2014

41. McGee TP, Houston CM and Brickley SG: Copper block of extrasynaptic GABAA receptors in the mature cerebellum and striatum. J Neurosci 33: 13431-13435, 2013.

42. Goldhaber SB: Trace element risk assessment: Essentiality vs. toxicity. Regul Toxicol Pharmacol 38: 232-242, 2003.

43. Montesano R, Rajewsky MF, Pegg AE and Miller E: Development and possible use of immunological techniques to detect individual exposure to carcinogens: International Agency for Research on Cancer/International Programme on Chemical Safety Working Group Report. Cancer Res 42: 5236-5239, 1982.

44. Rosival L and Vargová M: Chemization and human health. Czech Med 5: 131-136, 1982.

45. Lei R, Wu C, Yang B, Ma H, Shi C, Wang Q, Wang Q, Yuan Y and Liao M: Integrated metabolomic analysis of the nano-sized copper particle-induced hepatotoxicity and nephrotoxicity in rats: A rapid in vivo screening method for nanotoxicity. Toxicol Appl Pharmacol 232: 292-301, 2008.

46. Sharma M: Understanding the mechanism of toxicity of carbon nanoparticles in humans in the new millennium: A systemic review. Indian J Occup Environ Med 14: 3-5, 2010. 